\title{
Connexin 32 and connexin 43 are involved in lineage restriction of hepatic progenitor cells to hepatocytes
}

\author{
Haiyun Pei ${ }^{1,3 \dagger}$, Chao Zhai ${ }^{1 \dagger}$, Huilin Li ${ }^{1}$, Fang Yan², Jinhua Qin ${ }^{1,2,3}$, Hongfeng Yuan ${ }^{1}$, Rui Zhang ${ }^{1}$, Shuyong Wang ${ }^{1,2,3}$,
} Wencheng Zhang ${ }^{1}$, Mingyang Chang ${ }^{2}$, Yunfang Wang ${ }^{2^{*}}$ and Xuetao Pei ${ }^{1,3^{*}}$

\begin{abstract}
Background: Bi-potential hepatic progenitor cells can give rise to both hepatocytes and cholangiocytes, which is the last phase and critical juncture in terms of sequentially hepatic lineage restriction from any kind of stem cells. If their differentiation can be controlled, it might access to functional hepatocytes to develop pharmaceutical and biotechnology industries as well as cell therapies for end-stage liver diseases.

Methods: In this study, we investigated the influence of Cx32 and Cx43 on hepatocyte differentiation of WB-F344 cells by in vitro gain and loss of function analyses. An inhibitor of Cx32 was also used to make further clarification. To reveal p38 MAPK pathway is closely related to CXs, rats with 70\% partial hepatectomy were injected intraperitoneally with a p38 inhibitor, SB203580. Besides, the effects of p38 MAPK pathway on differentiation of hepatoblasts isolated from fetal rat livers were evaluated by addition of SB203580 in culture medium.

Results: In vitro gain and loss of function analyses showed overexpression of Connexin 32 and knockdown of Connexin 43 promoted hepatocytes differentiation from hepatic progenitor cells. In addition, in vitro and ex vivo research revealed inhibition of p38 mitogen-activated protein kinase pathway can improve hepatocytes differentiation correlating with upregulation of Connexin 32 expression and downregulation of Connexin 43 expression.

Conclusions: Here we demonstrate that Connexins play crucial roles in facilitating differentiation of hepatic progenitors. Our work further implicates that regulators of Connexins and their related pathways might provide new insights to improve lineage restriction of stem cells to mature hepatocytes.
\end{abstract}

Keywords: Connexin, p38 MAPK, Hepatic progenitor cell, Hepatocyte, Differentiation, Cell therapy

\section{Background}

With multiple functions of synthesis and detoxification, hepatocytes are great value to promote development of the pharmaceutical and biotechnology industries as well as cell transplantation for the treatment of end-stage liver diseases [1]. However, its application has been terribly impeded by limitations and scarcity of donor tissue, inability of proliferation, difficulties in cryopreservation,

\footnotetext{
*Correspondence: wangyf2011126@126.com; peixt@nic.bmi.ac.cn

Yunfang Wang and Xuetao Pei are co-senior authors.

${ }^{\dagger}$ Equal contributors

${ }^{2}$ Tissue Engineering Lab, Beijing Institute of Transfusion Medicine, Beijing 100850, China

'Stem Cell and Regenerative Medicine Lab, Beijing Institute of Transfusion Medicine, Beijing 100850, China

Full list of author information is available at the end of the article
}

deprivation of functions and de-differentiation in vitro [2]. An alternative that is becoming available is to generate fully functional hepatocytes from lineage restriction of stem cells. With pluripotency and unlimited selfrenewal capacity, pluripotent stem cells (PSCs), including embryonic stem cells (ESCs) and induced pluripotent stem cells (iPSCs), could be ideal sources of hepatocytes for clinical and industrial applications [3-6]. Nevertheless, so far, PSCs-derived hepatocytes usually possessed fetal hepatocyte-like phenotype and functions, which indicated that the key step for the final stage from hepatic progenitor cells to functional maturation of hepatocytes was the major challenge among the step-wised differentiation [7]. Consequently, it is highly necessary to make further clarification on mechanism of hepatic progenitors' 
differentiation to develop optimized strategy for derivation of hepatocytes.

Gap junctions are the pores coupling adjacent cells to mediate intercellular activities of gap junctional intercellular communication (GJIC), which are thought to function as a channel for exchange of materials between cells [8]. They are formed by connexons, "iris-diaphragm-like" structures composed of six connexin $(\mathrm{Cx})$ protein subunits. The $\mathrm{Cx}$ family is divided into 13 different members according to molecular weight. Previous research uncovered crucial roles of Cxs in stem cell proliferation and differentiation, for instance, modulation of $\mathrm{Cx} 43$ involved in differentiation of osteoblast [9], odontoblast [10], and lens epithelial cells [11].

In adult liver, Cx32, occupied approximately 90\% of Cxs on hepatic parenchymal cells, establishes an elaborate GIIC network between hepatocytes and becomes indispensable for liver development [12]. Dozens of studies have confirmed that Cx32 expression was strongly and positively correlated with multiple functions of hepatocytes, including glycogenolysis [13, 14], albumin (Alb) secretion [15], ammonia detoxification [15], bile secretion [16], and CYP (cytochrome P450)-mediated biotransformation [17-19]. What is more notable is that $\mathrm{Cx}$ expression patterns undergo lineage stage-dependent transformation in embryonic liver. Especially, a switch from Cx43 to Cx32 expression has been proved upon differentiation from hepatic progenitor cells to hepatocytes [12, 20-22], which dropped us a hint that Cxs might signal commitment to hepatocytes differentiation from early progenitor cells in the liver. Besides, they may interact with other proteins as upregulators or down-effectors to play significant roles.

The p38 mitogen-activated protein kinase (p38 MAPK) pathway has been reported to be involved in the regulation of many stem cell types. In particular, it is essential for the proper differentiation of stem cells in hematopoietic [23], muscular [24], neural [25, 26], cardiac [27], pancreatic [28-30], lung [31], and skin [32, 33] tissues. Former studies showed that inhibition of p38 MAPK activity could regulate $\mathrm{Cx} 32$ or $\mathrm{Cx} 43$ in both rat neuronal stem cells and liver epithelial cells [34-36]. Moreover, in vivo research indicated that downregulation of $\mathrm{Cx} 32$ protein after partial hepatectomy could be reversed by the treatment of p38 MAPK inhibitor [37]. Last year, our lab further revealed that Cx32-mediated GIC was necessary for hepatocyte differentiation of human ESCs during stepwise hepatic lineage restriction and p38 MAPK inhibitor improved maturation of differentiated cells correlating with upregulation of $\mathrm{Cx} 32$ through inhibition of phosphorylationdependent degradation of Cxs [38].

Although the shift phenomenon of Cxs in liver development is well known, the function of Cxs in differentiation of hepatic progenitor cells and the relationship with p38 MAPK pathway remains largely unknown. In this study, we explored the function of Cxs by using WB-F344 cells (WB cells), a rat cell line with hepatic progenitor-like features, which has often been used as an in vitro model to study the differentiation of hepatic progenitor cells into hepatocytes [39-42]. In vitro gain and loss of function analyses showed overexpression of Cx32 and knockdown of Cx43 promoted hepatocyte differentiation from hepatic progenitor cells. Furthermore, p38 inhibitor, SB203580, can improve hepatocyte differentiation correlating with upregulation of $\mathrm{Cx} 32$ and downregulation of $\mathrm{Cx} 43$ expression. Our work implicates that Cxs play crucial roles in facilitating differentiation of hepatic progenitors. To the best of our knowledge, this study provides the first evidence of p38 MAPK pathway and Cxs involved in the lineage restriction of rat hepatic progenitors to hepatocytes.

\section{Methods}

\section{Plasmids, lentivirals, and inhibitors}

In order to knockdown rat $\mathrm{Cx} 43$, oligonucleotides were synthesized and cloned into the lentiviral vector $\mathrm{pSico} R$ PGK-puro (Addgene, Cambridge, MA, USA), which contains a selection cassette for puromycin. A shRNA against luciferase was subcloned into the same vector as a control (ShCX43 sense:

5'TAGTTGCTGCTGGACATGAATTCAAGAGATTCA TGTCCAGCAGCAACTTTTTTTC-3'; ShCX43 anti-sense: 5'TCGAGAAAAAAAGTTGCTGCTGGACATGAATCT CTTGAATTCATGTCCAGCAGCAACTA-3'). For overexpression of $\mathrm{Cx} 32$ and $\mathrm{Cx} 43$ respectively, the amplified rat $\mathrm{Cx} 32$ and $\mathrm{Cx} 43$ fragments subcloned into the lentiviral vector pBPLV. An empty pBPLV vector was used as a control.

Vesicular stomatitis virus G protein- (VSV-G) pseudotyped lentiviruses were produced using a four-plasmid transfection system as described previously [43]. Cells were infected overnight with recombinant lentivirus using a multiplicity of infection (MOI) of five in the presence of $5 \mathrm{ng} / \mathrm{ml}$ polybrene. For knockdown of $\mathrm{Cx} 43,3$ days after infection, cells were selected by culturing in $2 \mu \mathrm{g} / \mathrm{ml}$ puromycin for 3 days and then used for further experiments. For overexpression of $\mathrm{Cx} 32$ or the $\mathrm{Cx} 43, \mathrm{GFP}^{+}$cells were sorted by FACS before further experiments.

To explore the effects of Cx32 on hepatocyte differentiation, 2-aminoethoxydiphenyl borate (2-APB, Tocris, Minneapolis, MN, USA), which has been shown to directly inhibit [44] Cx32 gap junctions in vitro and effectively block [45] hepatic gap junction communication in vivo, were used to test $\mathrm{Cx} 32$ relevance.

\section{WB cells culture and differentiation}

The WB cells were grown in RPMI 1640 medium (Gibco, Waltham, MA, USA) supplemented with $10 \%$ fetal calf serum (Hyclone, Chicago, IL, USA), $200 \mathrm{IU} / \mathrm{ml}$ penicillin and $50 \mu \mathrm{g} / \mathrm{ml}$ streptomycin. Cells were grown in a $37^{\circ} \mathrm{C}$ 
humidified incubator containing 5\% $\mathrm{CO}_{2}$. For differentiation to hepatocyte-like cells, WB cells were plated on Matrigel (60\%) and collagen IV (40\%)-coated plastic cell culture dishes at a density of $7 \times 10^{4}$ cells $/ \mathrm{cm}^{2}$. The cultures were incubated in Hepatocyte Medium (Sciencell, Carlsbad, CA, USA) supplemented with $25 \mathrm{ng} / \mathrm{ml}$ hepatocyte growth factor (HGF), $10 \mathrm{ng} / \mathrm{ml}$ oncostatin M (OSM), $1 \mu \mathrm{M}$ dexamethasone (Dex), $5 \mathrm{ng} / \mathrm{mL}$ insulin, and $10 \mathrm{ng} /$ $\mathrm{ml}$ epidermal growth factor (EGF) for 7 days.

It has been reported that Matrigel could induce differentiation of WB-F344 cells into biliary cells [46, 47]. For Matrigel-induced cholangiocyte differentiation, 50\% Matrigel was spread on a six-well plate and allowed to settle for at least $30 \mathrm{~min}$ at $37^{\circ} \mathrm{C}$. Cells were then plated at a density of $2 \times 10^{5}$ cells per well and cultured in basal medium supplemented with $5 \%$ fetal calf serum (Hyclone), $50 \mathrm{ng} / \mathrm{ml}$ epidermal growth factors (PeproTech, Rocky Hill, NJ, USA), $30 \mathrm{ng} / \mathrm{ml}$ insulin-like growth factor II (PeproTech) and $10 \mathrm{mg} / \mathrm{ml}$ insulin (R\&D Systems, Minneapolis, MN, USA) for 5 days.

\section{Isolation and culture of rat hepatocytes and hepatic stem cells}

Fisher 344 rats purchased from Vital River (Beijing, China) were maintained under a constant $12 \mathrm{~h}$ light/dark cycle and fed a standard rodent chow and water. Rats weighing 180-200 g were anesthetized with ketamine and xylazine via intraperitoneal and primary hepatocytes were freshly isolated by the two-step liver perfusion method of Seglen [48]. Eighteen-day-pregnant rats were anesthetized in the same way and the protocol for the hepatic stem cell isolation was as described [49]. Briefly, the fetal liver tissue was enzymatically processed by $300 \mathrm{U} / \mathrm{ml}$ type IV collagenase and $0.3 \mathrm{mg} / \mathrm{ml}$ deoxyribonuclease at $37{ }^{\circ} \mathrm{C}$ with frequent agitation for $20 \mathrm{~min}$. Enriched suspensions were pressed through a 75-gauge mesh and spun at $1200 \mathrm{rpm}$ for $5 \mathrm{~min}$ before resuspension. Isolated single cells were selectively cultured on $10-\mathrm{cm}$ well plates at $8 \times 10^{4} \mathrm{cells} / \mathrm{cm}^{2}$ in Kubota's Medium. The rats were euthanized after the hepatocytes isolation and the fetus extraction.

\section{Quantitative real time-polymerase chain reaction (qRT-PCR) analysis}

Total RNA was extracted using RNeasy Plus Mini Kit (Qiagen, Hilden, Germany) as per the manufacturer's instructions. Reverse Transcription was carried out with the SuperScript First-Strand Synthesis System for RT-PCR (Invitrogen, Carlsbad, CA, USA). HotStarTaq Master Mix Kit (Bio-Rad, Hercules, CA, USA) was used for PCR. Real-time PCR was carried out in the Bio-Rad IQ5 amplification system (Bio-Rad), and the results were calculated using the delta-delta CT method. PCR primers are listed in Table 1.
Table 1 Primers used for real-time PCR

\begin{tabular}{|c|c|}
\hline Rat-Cx43-S & TCTGCCTITCGCTGTAACACT \\
\hline Rat-Cx43-AS & GGGCACAGACACGAATATGAT \\
\hline Rat-CX32-S & CCAGGGCTCAAGGTTATTGA \\
\hline Rat-CX32-AS & TCTCCATCCACAGTGCAGAG \\
\hline Rat-Afp-S & ACCTGACAGGGAAGATGGTG \\
\hline Rat-Afp-AS & GCAGTGGTTGATACCGGAGT \\
\hline Rat-Alb-S & AATTGGCAACAGACCTCACC \\
\hline Rat-Alb-AS & GCACTGGCTTATCACAGCAA \\
\hline Rat-CYP1B1-S & CCCGTGGTGGTGCTGAAT \\
\hline Rat-CYP1B1-AS & AAAGAGGCGAAGGGAGGC \\
\hline Rat-CK18-S & TITGCGAATTCTGTGGACAA \\
\hline Rat-CK18-AS & ACCTCGTGATGTTGGTGTCA \\
\hline Rat-CK19-S & CCACACTACGCAGATCCAGA \\
\hline Rat-CK19-AS & ATGCTGAGCTGAGACTGCAA \\
\hline Rat-Hnf1a-S & ACCAGTCCCACAGTGTCCTC \\
\hline Rat-Hnf1a-AS & GCCATCTGGGTGGAGATAAA \\
\hline Rat-Hnf4a-S & AAATGTGCAGGTGTTGACCA \\
\hline Rat-Hnf4a-AS & CACGCTCCTCCTGAAGAATC \\
\hline Rat-Ggt4-S & GTCACCAACTTCAACTCTGC \\
\hline Rat- Ggt4-AS & CCTTATCACTGTITACCTCGG \\
\hline Rat-Hnf6-S & GAAAATAAGCGTCCGTCCAAAG \\
\hline Rat-Hnf6-AS & CTGGCATTCATGAAGAAGTTGC \\
\hline Rat-GAPDH-S & TGCCACTCAGAAGACTGTGG \\
\hline Rat-GAPDH-AS & TTCAGCTCTGGGATGACCTT \\
\hline
\end{tabular}

$S$ sense, $A S$ anti-sense

\section{Western blotting}

Proteins were extracted from the cultured cells with RIPA buffer (50 mM Tris-HCl. pH 7.5, 150 mM NaCl, 1\% NP-40, $0.5 \%$ sodium deoxycholate, $0.1 \%$ SDS) containing protease inhibitors (Roche, Basel, Switzerland). Protein concentrations were measured using the Bradford method (Bio-Rad) and then $80 \mathrm{~g}$ of total lysate from each sample was used to perform Western blot. Antibodies used included sheep antirat albumin (Bethyl Laboratories Montgomery, TX, USA), rabbit anti-rat Cyp1b1 (Santa Cruz Biotechnology, Dallas, TX, USA), rabbit anti-rat Cx32 (Abcam, Cambridge, MA, USA), rabbit anti-Rat Cx43 (Abcam), and rabbit antiphospho-p38 MAPK/p38 MAPK antibodies (Cell Signaling Technology, Danvers, MA, USA).

\section{Immunostaining}

Cells were fixed with $4 \%$ paraformaldehyde for $20 \mathrm{~min}$ at room temperature and blocked with $10 \%$ goat or donkey serum for $1 \mathrm{~h}$. The primary antibodies were incubated with the cells at $4{ }^{\circ} \mathrm{C}$ overnight and secondary antibodies were incubated for $45 \mathrm{~min}$ at room temperature. After being washed with PBS 3 times, the cells were examined under confocal laser microscope. Confocal images were 
collected by an LSM 510 META confocal system (Carl Zeiss, Oberkochen, Germany).

\section{Cell viability assay}

Hepatocytes derived from progenitors with overexpression of Connexin 32, knockdown of Connexin 43 or inhibition of p38 MAPK were digested with trypsin, counted, and then plated in a 96-well plate at a density of $1 \times 10^{3}$ per well. The measurement of viable cell mass was performed with a Cell Counting Kit (Dojin Laboratories, Kumamoto, Japan) to count living cells by WST-8.

\section{Flow cytometry analysis}

Hepatocytes derived from progenitors with or without inhibition of p38 MAPK were digested with trypsin, and then centrifuged at $1000 \mathrm{rpm}$ for $3 \mathrm{~min}$. Cells were washed three times with cool PBS and then stained with Annexin V FITC and PI solution for $15 \mathrm{~min}$ at room temperature in a dark environment. After adding Annexin V binding solution, the flow cytometry analysis can be carried out within 1 hour.

\section{Indocyanine green uptake}

After the cells were washed with PBS, indocyanine green (ICG) (Sigma-Aldrich, St Louis, MO, USA) solution was added at a final concentration of $1 \mathrm{mg} / \mathrm{ml}$. The cells were incubated with ICG at $37^{\circ} \mathrm{C}$ for $30 \mathrm{~min}$ and were rinsed three times in PBS, and then were examined microscopically.

\section{Urea synthesis}

The amounts of urea in the culture media were measured after the cells were incubated with $20 \mathrm{mM}$ ammonium chloride. Urea concentrations were determined by QuantiChrom Urea Assay Kit (BioAssay Systems, Hayward, CA, USA) according to the manufacturer's instructions.

\section{CYP induction and metabolism assay}

To evaluate CYP450 induction, differentiated cells were cultured with $25 \mu \mathrm{M}$ rifampicin for 3 days, with media changed every day. CYP3A4 activity was quantified using P450-GloTM CYP3A4 Luciferin-IPA kit (Promega, Madison, WI, USA) per manufacturer's instruction. Total cell numbers were used to normalize the data.

\section{Animal experiments}

Male Fisher 344 rats weighing about $40-50$ g were used in all experiments as animal models. All animal work was approved by the Institutional Animal Care and Use Committee (IACUC) at Beijing Institute of Transfusion Medicine (Reference number: IACUC of AMMS-2011183). Seventy percent partial hepatectomy $(\mathrm{PH})$ was performed. At $30 \mathrm{~min}$ before $\mathrm{PH}$ surgery, some rats were injected intraperitoneally with a SB203580 (Cell Signaling Technology), dissolved in $0.9 \% \mathrm{NaCl}$ at a dose of
$20 \mathrm{mg} / \mathrm{kg}$ body weight. The inhibitor was injected every 2 days. The rats injected DMSO were used as a control.

\section{Statistical analysis}

Data are shown as means and standard deviations. Twotailed Student's $t$ test was applied for calculating statistical probability in this study. $P$ values less than 0.05 were considered to be statistically significant.

\section{Results}

Cx32 expression was significantly increased but $\mathrm{Cx} 43$ expression was dramatically decreased in hepatocyte differentiation of WB cells

WB cells were small and polygonal and had a high nuclear/ cytoplasmic ratio when cultured on plastic in basal medium. After being induced with the hepatic differentiation conditions, the hepatocytes derived from WB cells (WB-Hep) became enlarged and more flattened, and expressed hepatocyte markers $A l b, C k 18$, and Cyp1b1; but those cells driven toward a biliary epithelial cell fate formed luminal structures, and gained cytoskeratin 19 (Ck19) and glutamyl transpeptidase 4 (Ggt4) expression, which is specifically induced in biliary cells (Fig. 1a, b). qRT-PCR result showed that WB cells expressed high $C \times 43$ and barely detectable $C \times 32$ (Fig. 1b, c), as previously reported [22]. Interestingly, when WB cells were differentiated into hepatocytes, expression of $C x 43$ decreased dramatically, while $C x 32$ expression was significantly increased. However, when WB cells were induced to biliary epithelial cells, we observed increased $C x 43$ expression and decreased $C \times 32$ expression (Fig. 1b). Furthermore, a shift from $\mathrm{Cx} 43$ to $\mathrm{Cx} 32$ expression during hepatic differentiation of WB cells was also confirmed by immunofluorescence staining and Western blotting (Fig. 1c, d).

\section{Cx32 and Cx43 were involved in the hepatic lineage restriction}

To investigate the roles of $\mathrm{Cx} 32$ and $\mathrm{Cx} 43$ during the differentiation of hepatic progenitor cells, in vitro gain and loss of function analyses were performed in WB cells. Recombinant lentivirus expressing Cx32, Cx43, and Cx43siRNA were used to achieve efficient overexpression of Cx32 and Cx43, and knockdown of Cx43 in WB cells (Fig. 2a). Under conditions for hepatocyte differentiation, cells with Cx32 overexpression showed much higher expression levels of hepatocyte markers [Alb, alpha fetoprotein (Afp), and Cyp1b1] than vector control. In contrast, overexpression of $\mathrm{Cx} 43$ decreased hepatocyte-specific genes. These results demonstrated that Cx32 overexpression promotes hepatocyte differentiation, whereas $\mathrm{Cx} 43$ overexpression inhibits hepatocyte differentiation. In addition, Cx43-supressing siRNA transfection upregulated the expression levels of hepatocyte markers, suggesting that $\mathrm{Cx} 43$ knockdown promotes hepatocyte differentiation (Fig. 2b, c). On the other hand, under conditions for cholangiocyte 

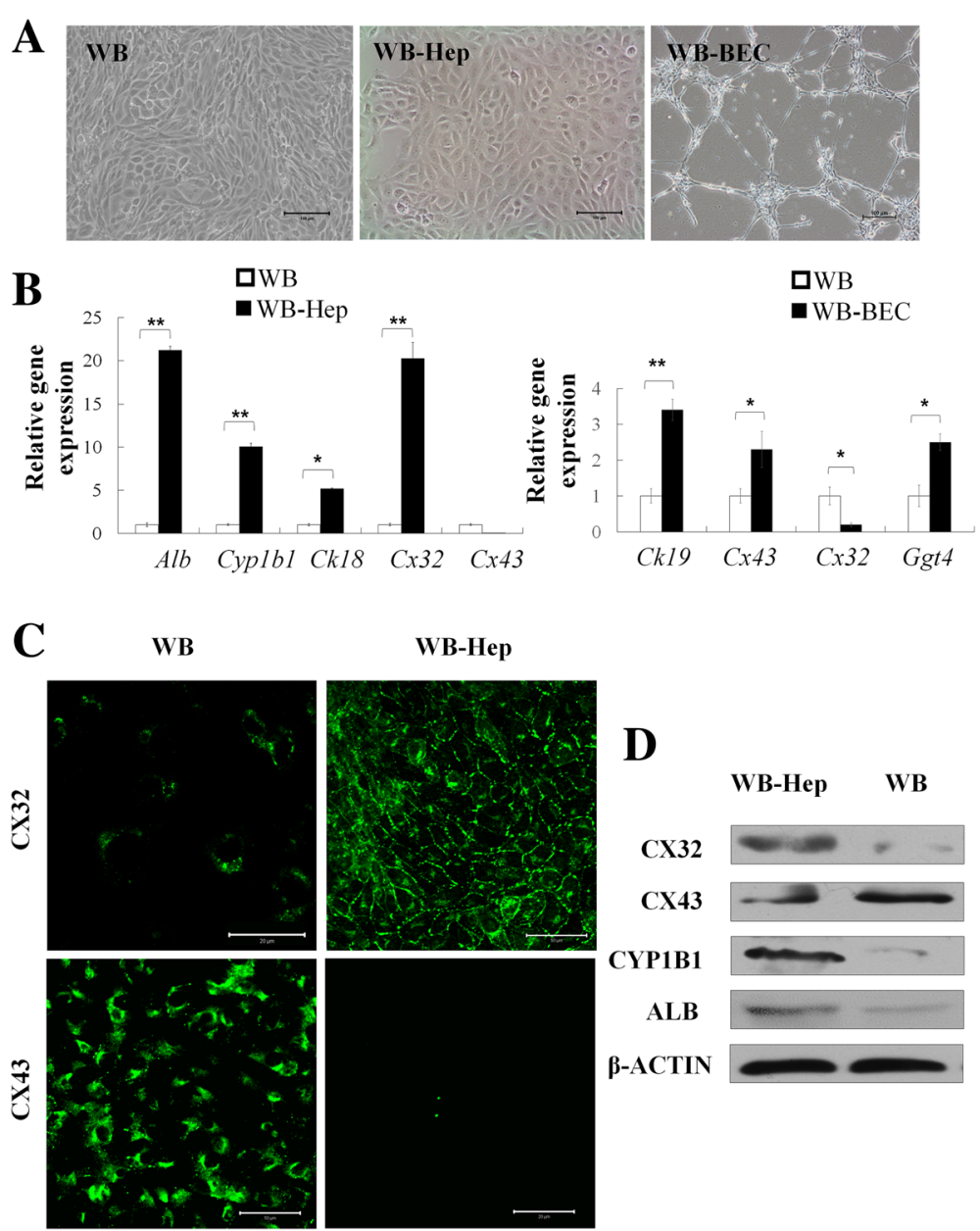

Fig. 1 The expression pattern of Cxs in differentiation of WB cells. a Representative images of WB cells, hepatocytes (WB-Hep) and biliary epithelial cells (WB-BEC) differentiated from WB cells. $\mathbf{b}$ qRT-PCR analysis of hepatic and biliary markers in WB-Hep and WB-BEC. $\mathbf{c}$ Immunostaining of Cx32 and Cx43 in WB cells and WB-Hep. d Western blotting of hepatic markers in WB cells and WB-Hep; $\beta$-actin was used as an internal control. Scale bars: $100 \mu \mathrm{m}$ for A and $50 \mu \mathrm{m}$ for C. Data represented as mean \pm SEM. ${ }^{*} p<0.05,{ }^{* *} p<0.01$

differentiation, cells with Cx43 overexpression combined with 2APB treatment showed much higher expression levels of biliary markers Ggt4, Ck19 and Hnf6 than vector control (Additional file 1: Figure S1A).

For function analysis, ICG uptake was tested. Most of cells turned to deep green after incubation with ICG for $30 \mathrm{~min}$ in $\mathrm{Cx} 32$ overexpression or $\mathrm{Cx} 43$ knockdown group, whereas few green cells appeared in Cx43 overexpression, 2APB, Cx43 overexpression plus 2APB group (Fig. 2d). In addition, after incubation with $20 \mathrm{mM}$ ammonium chloride, urea production in cell culture supernatant was much higher in Cx32 overexpression or Cx43 knockdown groups than that in the control group, and was lower in the 2-APB or $\mathrm{Cx} 43$ overexpression group (Fig. 2e). Taken together, these findings show that Cx32 and Cx43 are closely correlated with the differentiation of bi-potential hepatic progenitor cells.
Inhibition of p38 MAPK activity promoted the differentiation of hepatic progenitor cells associating with modulation of $\mathrm{C} \times 32$ and $\mathrm{Cx} 43$

During the process of hepatic progenitors differentiating into hepatocytes, phosphorylation level of p38 MAPK was decreased, compared to total levels of p38 MAPK (Fig. 3a), which suggested that p38 MAPK activity was negatively related to hepatocyte differentiation. Moreover, when a p38 MAPK inhibitor SB203580 was introduced in the hepatocyte differentiation medium, hepatocytes derived from WB cells expressed higher levels of hepatocyte markers Alb and Cyp1b1, with downregulation of Cx43 and upregulation of Cx32, as shown by qRT-PCR and Western blotting assays (Fig. 3b, c). Whereas, the expression of hepatocyte markers was much lower in WB cells with $\mathrm{Cx} 43$ overexpression, even under the treatment of SB203580, indicating that the enhancement of hepatocyte 

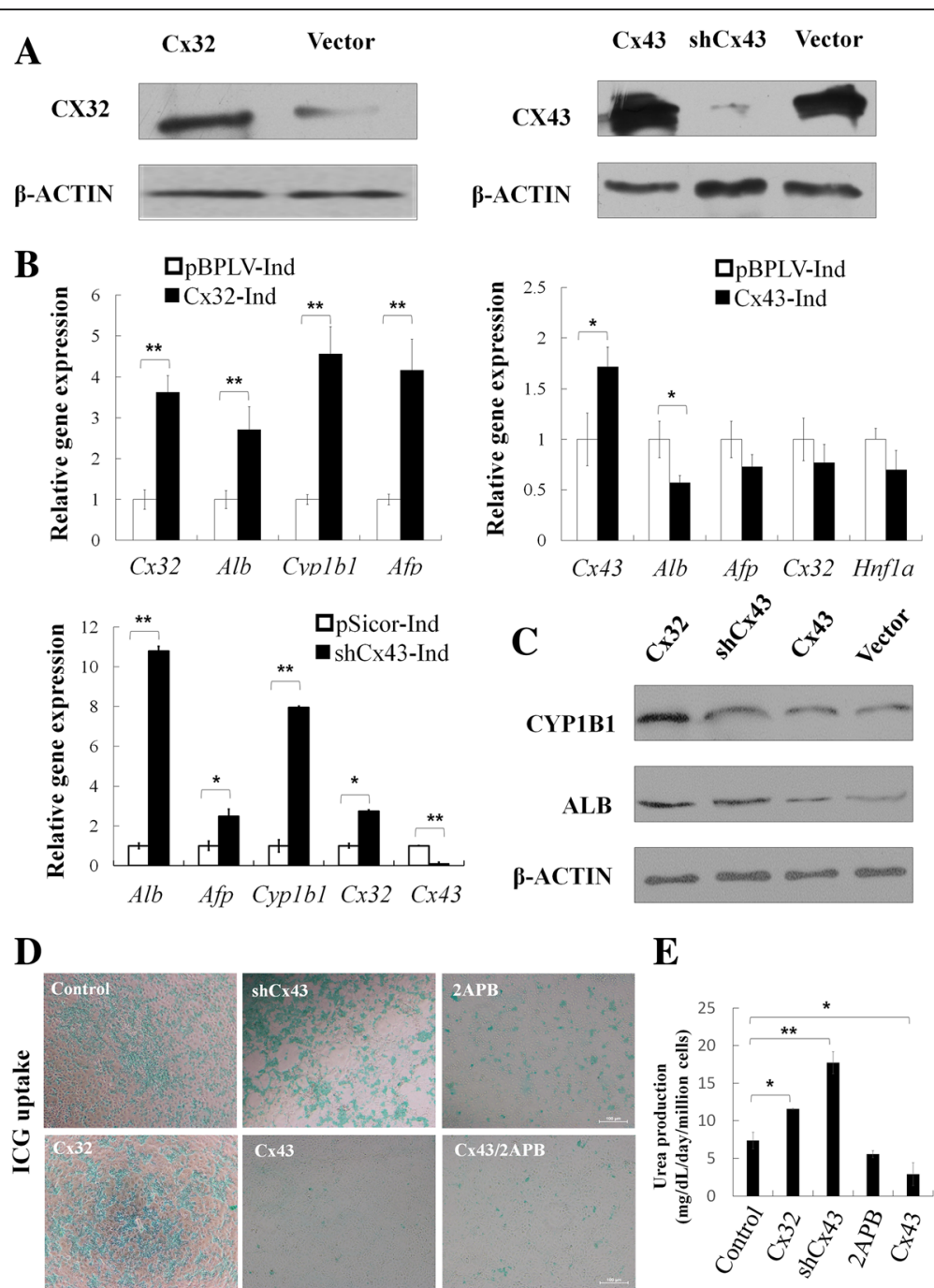

$\mathbf{E}$

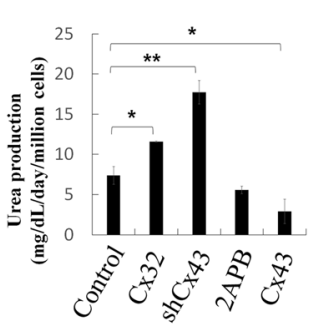

Fig. 2 Hepatocyte differentiation from hepatic progenitor cells was affected by Cxs expression. a Overexpression of Cx32 and Cx43, and knockdown of Cx43 in WB cells were confirmed by Western blotting. $\mathbf{b}$ qRT-PCR analysis of hepatic markers in cells differentiated from WB cells with Cx32 or Cx43 overexpression, or Cx43 knockdown. c Western blotting of hepatic markers in cells differentiated from WB cells with Cx32 or Cx43 overexpression, or Cx43 knockdown. d ICG uptake. e Urea production of WB cells with Cx32 or Cx43 overexpression, 2APB, or Cx43 knockdown. Scale bars: $100 \mu$ m. Data represented as mean \pm SEM. ${ }^{*} p<0.05,{ }^{* *} p<0.01$

differentiation by SB203580 was compromised by Cx43 overexpression (Fig. 3d, e).

In addition, to further confirm the closed relationship between p38 MAPK pathway and modulation of Cxs in vivo, rats were injected intraperitoneally with SB203580 at $30 \mathrm{~min}$ before PH surgery. After that, the expression of Cx43 was downregulated, whereas that of Cx32 was upregulated (Additional file 1: Figure S1B).

To further assess the effectiveness of SB203580 under stressful stimuli, CCL4-induced hepatocytes damage model and $\mathrm{H} 2 \mathrm{O} 2$ induced oxidative damage model in vitro were established. Incubation of cells with $8 \mathrm{mM} \mathrm{CCL} 4$ or $600 \mathrm{uM}$ $\mathrm{H} 2 \mathrm{O} 2$ for $1 \mathrm{~h}$ resulted in apoptosis and necrosis in hepatocytes derived from WB cells ( $24.3 \%$ and $32.2 \%$ respectively) but obvious decrease under the treatment of SB203580 as shown by the results of a MTT assay and flow cytometry, indicating that SB203580 can resist the cytotoxicity, reduce the apoptosis, promote proliferation and then protect against hepatocyte injury (Fig. 3f and g). For function analysis, ICG uptake was tested. Most of cells turned to deep green after incubation with ICG for 30 min in SB203580 group (Fig. 3h). Importantly, a sensitive and selective bioluminescent assay also confirmed CYP3A4 activity, which was inducible by rifampicin and improved by SB203580 (Fig. 3i).

\section{Cx32/Cx43 regulated hepatocytes differentiation via Hnf1a and Hnf4a}

Hepatocyte nuclear factors (HNFs) are a group of important transcription factors that regulate liver-specific gene expression. We found that expression of Hnfla and Hnf4a 

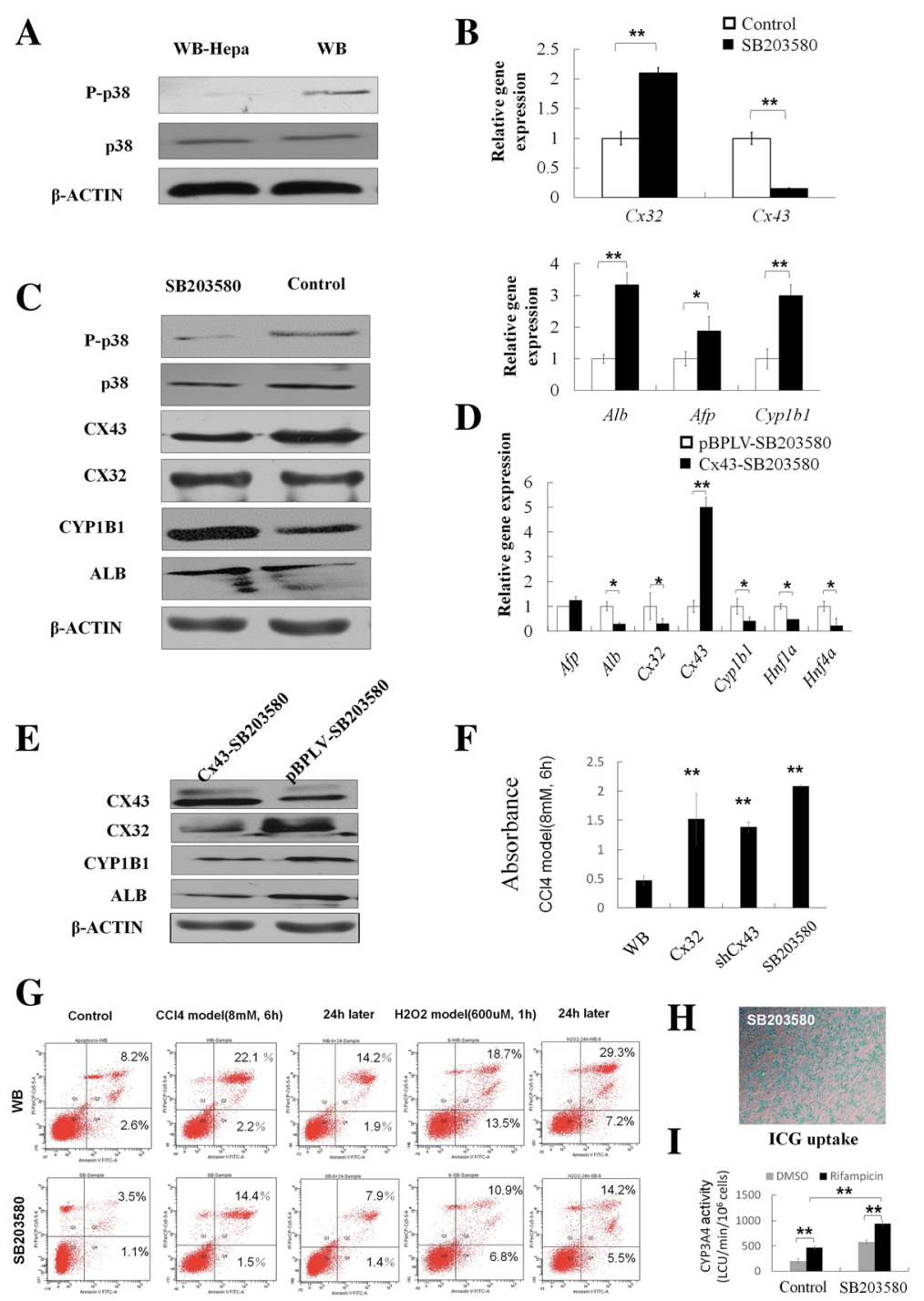

Fig. 3 p38 MAPK pathway affected hepatocytes differentiation associating with downregulation of Cx43 and upregulation of Cx32. a Western blotting of phospho-p38 (P-p38) and total p38 in WB cells and WB-Hep. b qRT-PCR analysis of WB-Hep induced with or without SB203580 treatment. c Western blotting of WB-Hep induced with or without SB203580 treatment. $\mathbf{d}$ qRT-PCR analysis of WB-Hep induced with SB203580 from WB cells and Cx43-overexpressed WB cells. e Western blotting of WB-Hep induced with SB203580 from WB cells and CX43-overexpressed WB cells. $\mathbf{f}$ Cell viability test by CCK8. $\mathbf{g}$ Flow cytometry analysis of apoptosis. $\mathbf{h}$ ICG uptake. $\mathbf{i}$ Induction of CYP3A4 activity in response to 72 hours of stimulation with PXR agonist rifampicin. Data represented as mean \pm SEM. ${ }^{*} p<0.05,{ }^{* *} p<0.01$

were significantly upregulated in hepatocytes differentiated from WB cells with Cx32 overexpression or Cx43 knockdown, while downregulated in cells with $\mathrm{Cx} 43$ overexpression (Fig. 4a). Furthermore, Hnfla and Hnf4a expression were greatly enhanced during hepatocyte differentiation of WB cells with the treatment of SB203580 (Fig. 4b). These data offer circumstantial evidence for critical roles of Cxs and p38MAPK pathway in hepatocyte differentiation.

\section{p38 MAPK affected differentiation of fetal hepatic progenitor cells}

To verify the intimate relationship between p38 MAPK pathway and Cxs expression ex vivo, primary hepatic progenitor cells were isolated from fetal rat livers, while primary rat hepatocytes were isolated from adult liver as control (Additional file 1: Figure S1C). When fetal rat hepatic progenitor cells were differentiated into hepatocytes, Cx32 expression was upregulated, while $\mathrm{Cx} 43$ expression was downregulated. After treatment by SB203580, primary hepatic progenitor cells expressed higher levels of hepatocyte markers Alb and Cyp1b1 associating with downregulation of $\mathrm{Cx} 43$ and upregulation of $\mathrm{Cx} 32$ (Fig. 5a, b).

\section{Discussion}

Stem cells represent a promisingly potential source of cells for regeneration and it is quite important to understand 

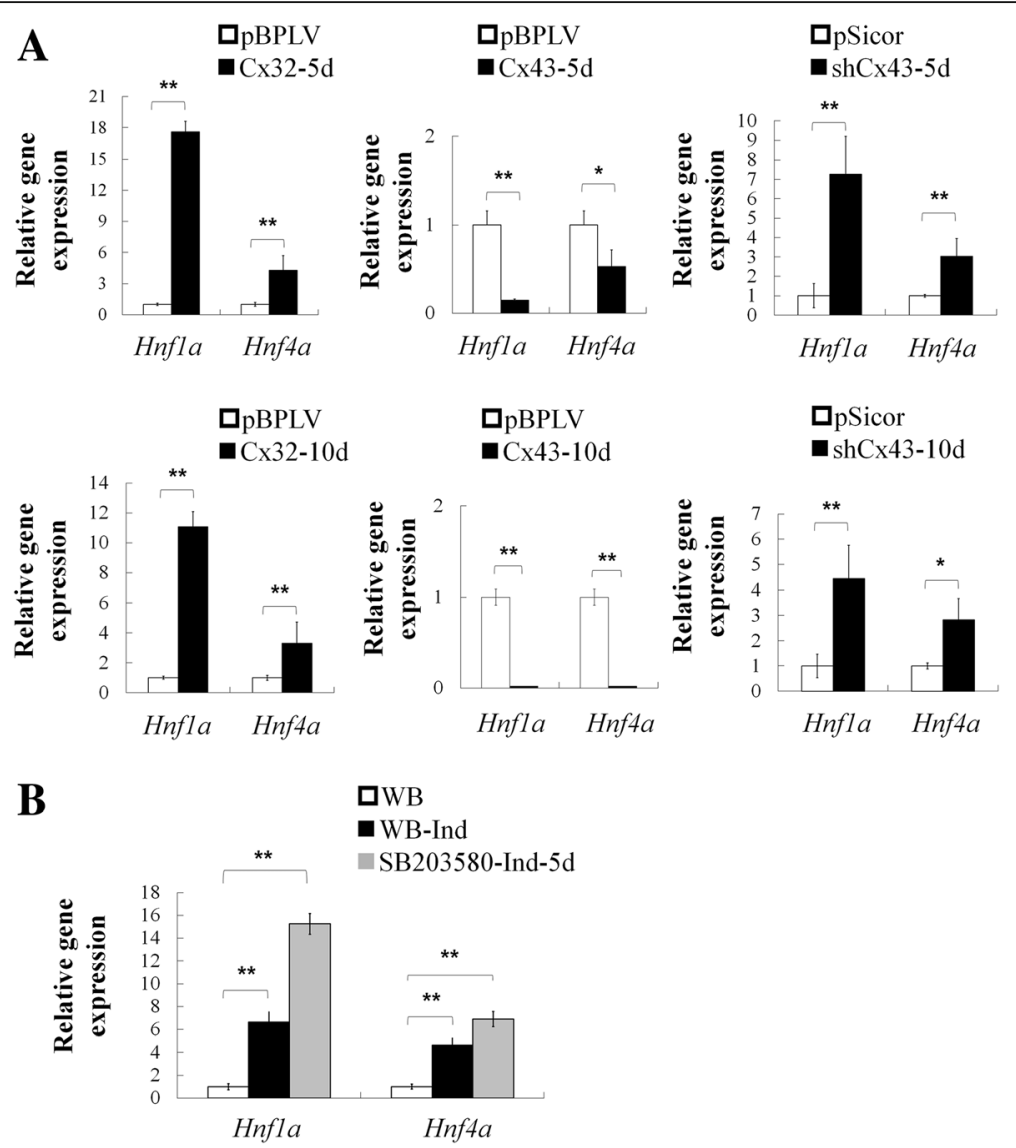

Fig. 4 p38 MAPK pathway and expression level of Cxs have an effect on Hnfla and Hnf4a in differentiation of hepatic progenitors. a qRT-PCR analysis of Hnf1a and Hnf4a expression in WB-Hep at day 5 and day 10 induced from WB cells with Cx32 or Cx43 overexpression, or Cx43 knockdown. $\mathbf{b}$ qRT-PCR analysis of Hnf1a and Hnf4a expression in WB cells and WB-Hep induced with or without SB203580 treatment. Data represented as mean \pm SEM. ${ }^{*} p<0.05$, ${ }^{* *} p<0.01$

the mechanism involved in stem cell differentiation. Until now, it has not been reported the essential relationship and mechanism between Cxs and differentiation of rat hepatic progenitors. In the present study, we confirm critical roles of Cxs on differentiation. Furthermore, we reveal that p38 MAPK pathway play a significant effect on lineage restriction of rat hepatic progenitors to hepatocytes associating with modulation of Cx32 and Cx43.

GJIC maintains normal growth and differentiation of cells in many tissues. In rat liver, $\mathrm{Cx} 32$, a fundamental element of GJIC, becomes detectable in the late stages of gestation and reaches maximal levels about 1 week after birth [50]. In addition, most of liver-specific functions are known to be related with Cx32 expression such as albumin secretion, ammonia detoxification, glycogenolysis, bile secretion, and xenobiotic phase I biotransformation. Most importantly, Cx expression patterns undergo lineage stage-dependent transformation in embryonic liver. The above phenomena hint that Cxs might play important roles in development and maturation of hepatic progenitor cells. In our study, qRTPCR and Western blotting assays showed that WB cells expressed high level of $\mathrm{Cx} 43$ and barely detectable Cx32.
When they differentiated into hepatocytes under the induction condition, Cx32 expression was dramatically increased while Cx43 expression was disappeared, which drew out a correlation between cell differentiation and the transformation of $\mathrm{Cx}$ expression patterns. To determine roles of $\mathrm{Cx} 32 / \mathrm{Cx} 43$ in regulating differentiation of hepatic progenitor cells, we established stable WB cell lines expressing $\mathrm{Cx} 32 / \mathrm{Cx} 43$ and shRNAs targeted-Cx43. In contrast to control cells, Cx32-overexpression and Cx43-downregulation cells more efficiently differentiated into cells that expressed Alb, Cyp1b1 protein. Phenotypic and functional analyses provided more convincing evidence that Cxs are critical mediators in differentiation of hepatic progenitor cells.

The p38 MAPK pathway widely involved in development, regulating a large number of processes, including growth, embryonic development, and tissue homoeostasis [51]. Previous studies showed p38 MAPK activity in liver cancer tissue is significantly higher than that in the adjacent tissue and activation of p38MAPK signaling has an association with the invasive or metastatic potential in human hepatocellular carcinoma cells, which suggested that inactivation of p38 occurs in the normal/ 


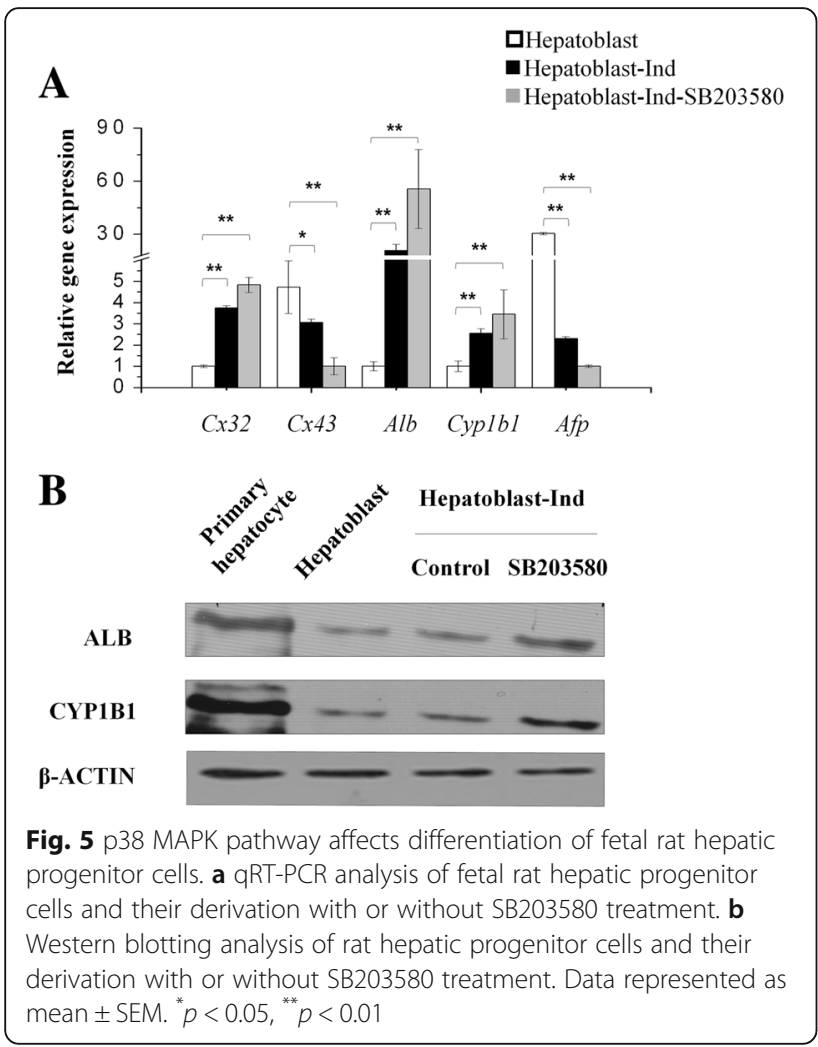

mature hepatocytes [52]. Besides, Cx32 was investigated in connection with p38 in rat hepatocytes [34]. Yang et al. also found p38 MAPK signaling pathway may be functionally related to regulation of gap junction in rat neuronal stem cell-derived cells [36]. More interestingly, when p38 MAPK pathway was activated during partial hepatectomy associated with downregulation of Cx32, which can be reversed by SB203580 treatment [37]. More recently, some studies showed Cx32 protein decreased in primary cultures of rat hepatocytes following the treatment with a p38 MAPK activator, anisomycin [53]. Our findings showed inhibition of p38 MAPK pathway can promote hepatocyte differentiation from hepatic progenitor cells associating with upregulation of Cx32 expression and downregulation of $\mathrm{Cx} 43$ expression. To further confirm the closed relationship between p38 MAPK pathway and modulation of Cxs in vivo, we examined $\mathrm{Cx}$ expression in rat livers after 70\% partial hepatectomy (PH) by using a p38 MAPK inhibitor SB203580. With SB203580 treatment, upregulation of Cx32 expression and downregulation of $\mathrm{Cx} 43$ expression were observed at 24 hours after $\mathrm{PH}$. Apart from verification in vitro and in vivo, we also demonstrated our hypothesis by ex vivo analysis. Our results showed that inhibition of p38 MAPK pathway remarkably improve hepatocytes differentiation from freshly isolated rat fetal hepatic progenitor cells accompanied by a shift from Cx43 to Cx32 expression.

\section{Conclusions}

In summary, we demonstrate that Cxs play crucial roles in facilitating differentiation of hepatic progenitors. Also, p38 MAPK pathway has a strong bond with Cxs modulation, which highly affects the last phase of hepatic lineage restriction. Our work further implicates that regulators of Cxs and their related pathways might provide new insights to improve lineage restriction of stem cells to mature hepatocytes. With further efforts, we expect to use this clue to derive functional hepatocytes for widely medical applications. Certainly, it will also be a new starting point for understanding of hepatic differentiation.

\section{Additional file}

Additional file 1: Figure S1. (A) qRT-PCR analysis of biliary markers in cells differentiated from WB cells with Cx43 overexpression combined with 2APB treatment. (B) Western blotting for phospho-p38 (P-p38), total p38, Cx32, and CX43 in rat livers treated with or without SB203580 for $24 \mathrm{~h}$ after partial hepatectomy. Each condition was spliced from a single gel to remove intervening lanes. (C) Morphology of primary hepatocytes derived from adult rat livers and hepatoblasts isolated from fetal rat livers. Scale bars: $100 \mu \mathrm{m}, 50 \mu \mathrm{m}, 25 \mu \mathrm{m}$ for B. Data represented as mean \pm SEM. ${ }^{*} p<0.05,{ }^{* *} p<0.01$. (TIF $4003 \mathrm{~kb}$ )

\section{Abbreviations}

Afp: Alpha fetoprotein; Alb: Albumin; Ck: Cytoskeratin; Cx: Connexin; cytochrome P450: CYP; Dex: Dexamethasone; EGF: Epidermal growth factor; ESCs: Embryonic stem cells; Ggt4: Glutamyl transpeptidase 4; GJIC: Gap junctional intercellular communication; HGF: Hepatocyte growth factor; HNFs: Hepatocyte nuclear factors; IACUC: Institutional Animal Care and Use Committee; ICG: Indocyanine green; iPSCs: Induced pluripotent stem cells; MOI: Multiplicity of infection; OSM: Oncostatin M; p38 MAPK: p38 mitogen-activated protein kinase; PH: Partial hepatectomy; PSCs: Pluripotent stem cells; VSV-G: Vesicular stomatitis virus G protein; WB cells: WB-F344 cells; WB-BEC: Biliary epithelial cells; WB-Hep: Hepatocytes derived from WB cells

\section{Acknowledgements}

We thank Dr. Ruolan Gu for her technical support.

\section{Funding}

This study was supported by the National Key Research and Development Program of China (No. 2017YFA0103103; No. 2016YFC1101305), Guangzhou Health Care and Cooperative Innovation Major Project (No. 201400000003-1; 201604020001), and National Nature Science Foundations of China (No. 31370990).

\section{Availability of data and materials}

Not applicable

\section{Authors' contributions}

HP and CZ contributed to the design of the initial studies, collection and assembly of data, data analyses and interpretation, and manuscript writing. $\mathrm{HY}$ helped in the early stages of the studies with experimental designs. $\mathrm{HL}$, $J Q, F Y$, and RZ contributed to animal experiments. HL, HY, JQ, SW, and WZ contributed to collection and assembly of data, data analyses. MC contributed to cell culture. YW contributed to conception and design, assembly of data, data analyses and interpretation, writing and editing of manuscript, and financial support. XP: contributed to editing and final approval of manuscript, and financial support. All authors read and approved the final manuscript.

\section{Ethics approval}

All animal work was approved by the Institutional Animal Care and Use Committee (IACUC) at Beijing Institute of Transfusion Medicine. 


\section{Competing interests}

The authors declare that they have no competing interests.

\section{Publisher's Note}

Springer Nature remains neutral with regard to jurisdictional claims in published maps and institutional affiliations.

\section{Author details}

${ }^{1}$ Stem Cell and Regenerative Medicine Lab, Beijing Institute of Transfusion Medicine, Beijing 100850, China. ${ }^{2}$ Tissue Engineering Lab, Beijing Institute of Transfusion Medicine, Beijing 100850, China. ${ }^{3}$ South China Institute of Biomedicine, Guangzhou 510005, China.

Received: 6 March 2017 Revised: 6 September 2017 Accepted: 19 October 2017 Published online: 07 November 2017

\section{References}

1. Lanzoni G, Oikawa T, Wang Y, Cui CB, Carpino G, Cardinale V, Gerber D, Gabriel M, Dominguez-Bendala J, Furth ME, et al. Clinical programs of stem cell therapies for liver and pancreas. Stem Cells. 2013:2047-60

2. Clayton DF, Darnell Jr JE. Changes in liver-specific compared to common gene transcription during primary culture of mouse hepatocytes. Mol Cell Biol. 1983;3:1552-61

3. Li F, Liu P, Liu C, Xiang D, Deng L, Li W, Wangensteen K, Song J, Ma Y, Hui $L$, et al. Hepatoblast-like progenitor cells derived from embryonic stem cells can repopulate livers of mice. Gastroenterology. 2010:139:2158-69. e2158.

4. Bukong TN, Lo T, Szabo G, Dolganiuc A. Novel developmental biologybased protocol of embryonic stem cell differentiation to morphologically sound and functional yet immature hepatocytes. Liver Int. 2012;32:732-41.

5. Zeng L, Chen C, Song G, Yan Z, Xu S, Jia L, Ding S, Cao J, Chen W, Cheng H, et al. Infusion of endothelial progenitor cells accelerates hematopoietic and immune reconstitution, and ameliorates the graft-versus-host disease after hematopoietic stem cell transplantation. Cell Biochem Biophys. 2012;64:213-22.

6. Pei H, Yang Y, Xi J, Bai Z, Yue W, Nan X, Bai C, Wang Y, Pei X. Lineage restriction and differentiation of human embryonic stem cells into hepatic progenitors and zone 1 hepatocytes. Tissue Eng Part C Methods. 2009;15:95-104.

7. Baxter M, Withey S, Harrison S, Segeritz CP, Zhang F, Atkinson-Dell R, Rowe C, Gerrard DT, Sison-Young R, Jenkins R, et al. Phenotypic and functional analyses show stem cell-derived hepatocyte-like cells better mimic fetal rather than adult hepatocytes. J Hepatol. 2015;62:581-9.

8. Saez JC, Connor JA, Spray DC, Bennett MV. Hepatocyte gap junctions are permeable to the second messenger, inositol 1,4,5-trisphosphate, and to calcium ions. Proc Natl Acad Sci U S A. 1989;86:2708-12.

9. Li Z, Zhou Z, Saunders MM, Donahue HJ. Modulation of connexin43 alters expression of osteoblastic differentiation markers. Am J Physiol Cell Physiol. 2006:290:C1248-55.

10. Li S, He H, Zhang G, Wang F, Zhang P, Tan Y. Connexin43-containing gap junctions potentiate extracellular $\mathrm{Ca}(2+)$-induced odontoblastic differentiation of human dental pulp stem cells via Erk1/2. Exp Cell Res. 2015;338:1-9.

11. Long AC, Bomser JA, Grzybowski DM, Chandler HL. All-trans retinoic Acid regulates cx43 expression, gap junction communication and differentiation in primary lens epithelial cells. Curr Eye Res. 2010;35:670-9.

12. Neveu MJ, Hully JR, Babcock KL, Vaughan J, Hertzberg EL, Nicholson BJ, Paul $\mathrm{DL}$, Pitot HC. Proliferation-associated differences in the spatial and temporal expression of gap junction genes in rat liver. Hepatology. 1995;22:202-12.

13. Nelles E, Butzler C, Jung D, Temme A, Gabriel HD, Dahl U, Traub O, Stumpel $F$, Jungermann K, Zielasek J, et al. Defective propagation of signals generated by sympathetic nerve stimulation in the liver of connexin32deficient mice. Proc Natl Acad Sci U S A. 1996:93:9565-70.

14. Stumpel F, Ott T, Willecke K, Jungermann K. Connexin 32 gap junctions enhance stimulation of glucose output by glucagon and noradrenaline in mouse liver. Hepatology. 1998;28:1616-20.

15. Yang J, Ichikawa A, Tsuchiya T. A novel function of connexin 32: marked enhancement of liver function in a hepatoma cell line. Biochem Biophys Res Commun. 2003;307:80-5.

16. Temme A, Stumpel F, Sohl G, Rieber EP, Jungermann K, Willecke K, Ott T. Dilated bile canaliculi and attenuated decrease of nerve-dependent bile secretion in connexin32-deficient mouse liver. Pflugers Arch. 2001:442:961-6.

17. Neveu MJ, Babcock KL, Hertzberg EL, Paul DL, Nicholson BJ, Pitot HC. Colocalized alterations in connexin32 and cytochrome P450IIB1/2 by phenobarbital and related liver tumor promoters. Cancer Res. 1994:54:3145-52.
18. Shoda T, Mitsumori K, Onodera H, Toyoda K, Uneyama C, Imazawa T, Hirose $\mathrm{M}$. The relationship between decrease in Cx32 and induction of P450 isozymes in the early phase of clofibrate hepatocarcinogenesis in the rat. Arch Toxicol. 1999:73:373-80.

19. Shoda T, Mitsumori K, Onodera H, Toyoda K, Uneyama C, Takada K, Hirose M Liver tumor-promoting effect of beta-naphthoflavone, a strong CYP 1A1/2 inducer, and the relationship between CYP 1A1/2 induction and CX32 decrease in its hepatocarcinogenesis in the rat. Toxicol Pathol. 2000;28:540-7.

20. Zhang M, Thorgeirsson SS. Modulation of connexins during differentiation of oval cells into hepatocytes. Exp Cell Res. 1994;213:37-42.

21. Rosenberg E, Faris RA, Spray DC, Monfils B, Abreu S, Danishefsky I, Reid LM. Correlation of expression of connexin mRNA isoforms with degree of cellular differentiation. Cell Adhes Commun. 1996:4:223-35.

22. Paku S, Nagy P, Kopper L, Thorgeirsson SS. 2-acetylaminofluorene dosedependent differentiation of rat oval cells into hepatocytes: confocal and electron microscopic studies. Hepatology. 2004;39:1353-61.

23. Navas TA, Mohindru M, Estes M, Ma JY, Sokol L, Pahanish P, Parmar S, Haghnazari E, Zhou L, Collins R, et al. Inhibition of overactivated p38 MAPK can restore hematopoiesis in myelodysplastic syndrome progenitors. Blood. 2006;108:4170-7.

24. Weston AD, Sampaio AV, Ridgeway AG, Underhill TM. Inhibition of p38 MAPK signaling promotes late stages of myogenesis. J Cell Sci. 2003;116:2885-93.

25. Zhang D, Guo M, Zhang W, Lu XY. Adiponectin stimulates proliferation of adult hippocampal neural stem/progenitor cells through activation of p38 mitogenactivated protein kinase (p38MAPK)/glycogen synthase kinase 3beta (GSK3beta)/beta-catenin signaling cascade. J Biol Chem. 2011;286:44913-20.

26. Oh JE, Bae GU, Yang YJ, Yi MJ, Lee HJ, Kim BG, Krauss RS, Kang JS. Cdo promotes neuronal differentiation via activation of the p38 mitogenactivated protein kinase pathway. FASEB J. 2009;23:2088-99.

27. Ambrosino C, Iwata T, Scafoglio C, Mallardo M, Klein R, Nebreda AR. TEF-1 and C/EBPbeta are major p38alpha MAPK-regulated transcription factors in proliferating cardiomyocytes. Biochem J. 2006;396:163-72.

28. Hanley S, Rosenberg L. Transforming growth factor beta is a critical regulator of adult human islet plasticity. Mol Endocrinol. 2007;21:1467-77.

29. Hamamoto K, Yamada S, Hara A, Kodera T, Seno M, Kojima I. Extracellular matrix modulates insulin production during differentiation of AR42J cells: functional role of Pax6 transcription factor. J Cell Biochem. 2011;112:318-29.

30. Ogihara T, Watada H, Kanno R, Ikeda F, Nomiyama T, Tanaka Y, Nakao A, German MS, Kojima I, Kawamori R. p38 MAPK is involved in activin A- and hepatocyte growth factor-mediated expression of pro-endocrine gene neurogenin 3 in AR42J-B13 Cells. J Biol Chem. 2003;278:21693-700.

31. Kim MJ, Park BJ, Kang YS, Kim HJ, Park JH, Kang JW, Lee SW, Han JM, Lee HW, Kim S. Downregulation of FUSE-binding protein and c-myc by tRNA synthetase cofactor p38 is required for lung cell differentiation. Nat Genet. 2003:34:330-6.

32. Connelly JT, Mishra A, Gautrot JE, Watt FM. Shape-induced terminal differentiation of human epidermal stem cells requires p38 and is regulated by histone acetylation. PLOS ONE. 2011;6, e27259.

33. Oeztuerk-Winder F, Ventura JJ. The many faces of p38 mitogen-activated protein kinase in progenitor/stem cell differentiation. Biochem J. 2012:445:1-10.

34. Kojima T, Yamamoto T, Lan M, Murata M, Takano K, Go M, Ichimiya S, Chiba $\mathrm{H}$, Sawada N. Inhibition of MAP kinase activity moderates changes in expression and function of Cx32 but not claudin-1 during DNA synthesis in primary cultures of rat hepatocytes. Med Electron Microsc. 2004;37:101-13.

35. Kojima T, Yamamoto T, Murata M, Lan M, Takano K, Go M, Ichimiya S, Chiba $\mathrm{H}$, Sawada N. Role of the p38 MAP-kinase signaling pathway for Cx32 and claudin-1 in the rat liver. Cell Commun Adhes. 2003;10:437-43.

36. Yang SR, Cho SD, Ahn NS, Jung JW, Park JS, Jo EH, Hwang JW, Jung JY, Kim TY, Yoon BS, et al. Role of gap junctional intercellular communication (GJIC) through p38 and ERK1/2 pathway in the differentiation of rat neuronal stem cells. J Vet Med Sci. 2005;67:291-4.

37. Yamamoto T, Kojima T, Murata M, Takano K, Go M, Hatakeyama N, Chiba H, Sawada N. p38 MAP-kinase regulates function of gap and tight junctions during regeneration of rat hepatocytes. J Hepatol. 2005;42:707-18.

38. Qin J, Chang M, Wang S, Liu Z, Zhu W, Wang Y, Yan F, Li J, Zhang B, Dou G, et al. Connexin 32-mediated cell-cell communication is essential for hepatic differentiation from human embryonic stem cells. Sci Rep. 2016;6:37388.

39. Zeng J, Jing Y, Shi R, Pan X, Lai F, Liu W, Li R, Gao L, Hou X, Wu M, Wei L. Autophagy regulates biliary differentiation of hepatic progenitor cells through Notch1 signaling pathway. Cell Cycle. 2016;15:1602-10. 
40. Jia Y, Yao H, Zhou J, Chen L, Zeng Q, Yuan H, Shi L, Nan X, Wang Y, Yue W, Pei $X$. Role of epimorphin in bile duct formation of rat liver epithelial stemlike cells: involvement of small G protein RhoA and C/EBPbeta. J Cell Physiol. 2011;226:2807-16.

41. Coleman WB, McCullough KD, Esch GL, Faris RA, Hixson DC, Smith GJ, Grisham JW. Evaluation of the differentiation potential of WB-F344 rat liver epithelial stem-like cells in vivo. Differentiation to hepatocytes after transplantation into dipeptidylpeptidase-IV-deficient rat liver. Am J Pathol. 1997;151:353-9.

42. Tsao MS, Smith JD, Nelson KG, Grisham JW. A diploid epithelial cell line from normal adult rat liver with phenotypic properties of 'oval' cells. Exp Cell Res. 1984;154:38-52.

43. Yuan H, Wang Z, Gao C, Chen W, Huang Q, Yee JK, Bhatia R, Chen W. BCR$\mathrm{ABL}$ gene expression is required for its mutations in a novel $\mathrm{KCL}-22$ cell culture model for acquired resistance of chronic myelogenous leukemia. J Biol Chem. 2010;285:5085-96.

44. Tao L, Harris AL. 2-aminoethoxydiphenyl borate directly inhibits channels composed of connexin26 and/or connexin32. Mol Pharmacol. 2007;71:570-9.

45. Patel SJ, Milwid JM, King KR, Bohr S, Iracheta-Vellve A, Li M, Vitalo A, Parekkadan B, Jindal R, Yarmush ML. Gap junction inhibition prevents druginduced liver toxicity and fulminant hepatic failure. Nat Biotechnol. 2012;30:179-83.

46. Couchie D, Holic N, Chobert MN, Corlu A, Laperche Y. In vitro differentiation of WB-F344 rat liver epithelial cells into the biliary lineage. Differentiation. 2002;69:209-15.

47. Yao H, Jia Y, Zhou J, Wang J, Li Y, Wang Y, Yue W, Pei X. RhoA promotes differentiation of WB-F344 cells into the biliary lineage. Differentiation. 2009;77:154-61.

48. Seglen PO. Preparation of rat liver cells. I. Effect of Ca 2+ on enzymatic dispersion of isolated, perfused liver. Exp Cell Res. 1972;74:450-4.

49. Schmelzer E, Zhang L, Bruce A, Wauthier E, Ludlow J, Yao HL, Moss N, Melhem A, McClelland R, Turner W, et al. Human hepatic stem cells from fetal and postnatal donors. J Exp Med. 2007;204:1973-87.

50. Iwai M, Harada Y, Muramatsu A, Tanaka S, Mori T, Okanoue T, Katoh F, Ohkusa T, Kashima K. Development of gap junctional channels and intercellular communication in rat liver during ontogenesis. J Hepatol. 2000;32:11-8.

51. Roux PP, Blenis J. ERK and p38 MAPK-activated protein kinases: a family of protein kinases with diverse biological functions. Microbiol Mol Biol Rev. 2004;68:320-44

52. Hsieh YH, Wu TT, Huang CY, Hsieh YS, Hwang JM, Liu JY. p38 mitogenactivated protein kinase pathway is involved in protein kinase Calpharegulated invasion in human hepatocellular carcinoma cells. Cancer Res. 2007:67:4320-7.

53. Kamiya A, Nakauchi H. Enrichment and clonal culture of hepatic stem/ progenitor cells during mouse liver development. Methods Mol Biol. 2013;945:273-86.

\section{Submit your next manuscript to BioMed Central and we will help you at every step:}

- We accept pre-submission inquiries

- Our selector tool helps you to find the most relevant journal

- We provide round the clock customer support

- Convenient online submission

- Thorough peer review

- Inclusion in PubMed and all major indexing services

- Maximum visibility for your research

Submit your manuscript at www.biomedcentral.com/submit

) Biomed Central 